\title{
Versican Core Protein
}

National Cancer Institute

\section{Source}

National Cancer Institute. Versican Core Protein. NCI Thesaurus. Code C113263.

Versican core protein (3396 aa, $\sim 373 \mathrm{kDa}$ ) is encoded by the human VCAN gene. This protein is involved in both environmental signaling and proteoglycan metabolism. 